\title{
Contribution of programmed cell death 6 genetic variations, gender, and smoking status to lung
} cancer

\author{
Te-Chun Shen ${ }^{1-3, *}$ \\ Wen-Shin Chang ${ }^{1,2, *}$ \\ Te-Chun Hsia ${ }^{1,3,4, *}$ \\ Hsin-Ting Li' \\ Wei-Chun Chen ${ }^{3,4}$ \\ Chia-Wen Tsai ${ }^{1, *}$ \\ Da-Tian Bau ${ }^{1,2,5, *}$
}

'Terry Fox Cancer Research Laboratory, Translational Medicine Research Center, China Medical University Hospital,

Taichung, Taiwan; ${ }^{2}$ Graduate Institute of Clinical Medical Science, China Medical University, Taichung, Taiwan;

${ }^{3}$ Department of Internal Medicine, China Medical University Hospital, Taichung,

Taiwan; ${ }^{4}$ Department of Respiratory

Therapy, China Medical University,

Taichung, Taiwan; ${ }^{5}$ Department of

Bioinformatics and Medical Engineering,

Asia University, Taichung, Taiwan

*These authors contributed equally to this work
This article was published in the following Dove Press journal: OncoTargets and Therapy

Purpose: Programmed cell death 6 (PDCD6) is a calcium sensor participating in T-cell receptor-, Fas-, and glucocorticoid-induced programmed cell death. At the sites of lung tumors, the expression of PDCD6 is higher than that in non-tumor tissues. However, the contribution of variant PDCD6 genotypes to lung cancer is largely unknown. The current study aimed to evaluate the contributions of the PDCD6 rs4957014 and rs3756712 genotypes to the risk of lung cancer.

Patients and methods: The contributions of PDCD6 genotypes to lung cancer risk were examined among 358 patients with lung cancer and 716 age- and gender-matched healthy controls by typical polymerase chain reaction-restriction fragment length polymorphism (PCR-RFLP) methodology.

Results: The results showed that the GG but not the GT genotype of PDCD6 rs4957014 was associated with a decreased risk of lung cancer (odds ratio $(\mathrm{OR})=0.41,95 \%$ confidence interval $(\mathrm{CI})=0.23-0.72, p=0.0013$ ). The analysis of allelic frequency distributions showed that the G allele of PDCD6 rs4957014 decreased lung cancer susceptibility $(p=0.0090)$. There was no association between PDCD6 rs3756712 genotypes and lung cancer risk. Interestingly, the GG genotype at PDCD6 rs4957014 significantly decreased the risk of lung cancer among males (adjusted $\mathrm{OR}=0.29,95 \% \mathrm{CI}=0.14-0.57$ ) and smokers (adjusted $\mathrm{OR}=0.34,95 \% \mathrm{CI}=0.18-0.61$ ) but not among females and non-smokers.

Conclusion: The GG genotype of PDCD6 rs4957014 may decrease lung cancer risk in males and smokers and may serve as a practical marker for early detection and the incidence of lung cancer in Taiwan.

Keywords: genotype, lung cancer, male, programmed cell death 6 (PDCD6), polymorphism, smoking

\section{Introduction}

For decades, lung cancer has been the most commonly diagnosed cancer and the leading cause of cancer death all over the world. ${ }^{1-3}$ Although several anticancer therapeutic strategies and technologies are rapidly being developed, the prognosis of lung cancer patients remains very poor, as the overall 5-year survival rates are still less than $15-20 \%$. ${ }^{4,5}$ From an epidemiological viewpoint, the most commonly identified factor in lung development and carcinogenesis is believed to be the individual's longterm history of tobacco consumption, which is also a useful predictor of poor prognosis. $^{6-8}$ In this decade, many case-control studies have reported that specific genotypes are associated with higher lung cancer risk for cigarette smokers than for
Correspondence: Da-Tian Bau; Chia-Wen Tsai

Terry Fox Cancer Research Laboratory, Translational Medicine Research Center, China Medical University Hospital, 2 Yuh-Der Road, Taichung 404, Taiwan Tel +88642 2053366 (Ext. 5805) Email artbau2@gmail.com; wenwen8I6@gmail.com 
non-smokers ${ }^{9-17}$ and vice versa. ${ }^{18-21}$ In 2010, Lissowska and colleagues conducted a meta-analysis of 41 global studies and proposed that family lung cancer history, although often not well recorded, is a risk factor for lung cancer. ${ }^{22}$ The above studies elucidating the gene-lifestyle interactions in lung cancer risk, with or without attention to smoking status, may provide not only predictive markers for revealing the personalized etiology of lung cancer but also potential targets for personalized therapy and genomic pharmacology.

The PDCD6 gene, also known as apoptosis-linked gene 2 (ALG- 2), is located on human chromosome 5p15.33 and encodes the $22-\mathrm{kD}$ programmed cell death protein $6 .^{23,24}$ PDCD6 is a $\mathrm{Ca}^{2+}$-binding protein capable of interacting with Alix/AIP1 and their orthologs, ${ }^{25}$ ASK $1,{ }^{26}$ and Sec31A, ${ }^{27}$ so as to participate in T-cell receptor-, Fas-, glucocorticoid-, and ER stress-induced apoptosis. ${ }^{23,28}$ In a knockout animal model, PDCD6-deficient mice were developmentally and immunologically normal, indicating that PDCD6 is not essential for physical development or immune function. ${ }^{29}$ However, PDCD6-deficient cells were no longer capable of blocking apoptosis induced by TCR, FAS, or dexamethasone signals. ${ }^{29}$ The expression levels and genotypes ${ }^{30}$ of PDCD6 are associated with cancer risk. In 2003, it was found that PDCD6 was upregulated at tumor sites relative to non-tumor sites among lung cancer patients. ${ }^{31}$ With respect to lung cancer genomics, only one paper has investigated the association of PDCD6 genotypes with lung cancer risk. ${ }^{32}$ In that study, the T allele of rs3756712 G/T, but not that of rs $4957014 \mathrm{G} / \mathrm{T}$, was found to be associated with an increased risk of lung cancer. ${ }^{32}$ However, the positive findings reported by them should be validated by other studies, especially those conducted in Asian populations. Thus, in the present study, we aimed to investigate the contribution of PDCD6 genotypes at rs3756712 G/T and rs4957014 G/T single-nucleotide polymorphic sites to the risk of lung cancer and then to examine the joint effect of environmental factors, such as habitual smoking, and PDCD6 genotypes on lung cancer risk in Taiwan.

\section{Materials and methods}

\section{Methodology for population data collection}

First, we have evaluated the sample size for the study group and the estimated total sample size was 864 (432 in each group) while alpha $=5 \%$, power $=80 \%$, the proportion of homozygous mutant in the case group $=10 \%$, and the difference $=5 \%$. From 2005 to 2008 , data on 358 patients diagnosed with lung cancer were collected by the surgery team led by Hsia at the Outpatient Clinics of General Surgery of China
Medical University Hospital. The clinical characteristics of these lung cancer patients, including their histological details, were all graded and defined by well-trained doctors. The exclusion criteria were history of any other cancer or pulmonary disease, such as chronic obstructive pulmonary disease, pneumothorax, and asthma. Simultaneously, 716 healthy volunteers without lung cancer for every case were chosen as controls by matching for age, gender, and smoking behavior after initial random sampling from the Health Examination Cohort of China Medical University Hospital. The exclusion criteria of the controls included previous malignancy, metastasized cancer from another or an unknown origin, and any genetic or familial diseases. All participants in this project voluntarily completed a self-administered questionnaire and provided a 5-ml sample of peripheral blood for genotyping. The study was conducted in accordance with the Declaration of Helsinki and approved by the Institutional Review Board of the China Medical University Hospital with the document coded DMR100-IRB-284. Written informed consent was obtained from each participant with the help of the tissue bank. Typical characteristics of the subjects included in this study are summarized in Table 1.

\section{Methodology for PDCD6 genotyping}

Genomic DNA from peripheral blood leucocytes of each subject was extracted with a QIAamp Blood Mini Kit (Blossom, Taipei, Taiwan) and further stored and processed as previously described. ${ }^{16,17}$ Briefly, the polymerase chain reaction (PCR) cycling programs set for PDCD6 genotypes were the following: one cycle at $94{ }^{\circ} \mathrm{C}$ for $5 \mathrm{~min} ; 35$ cycles of $94{ }^{\circ} \mathrm{C}$ for $30 \mathrm{~s}, 55^{\circ} \mathrm{C}$ for $30 \mathrm{~s}$ and $72^{\circ} \mathrm{C}$ for $30 \mathrm{~s}$; and a final extension at $72{ }^{\circ} \mathrm{C}$ for $10 \mathrm{~min}$. The DNA sequences of the forward and reverse primers for PDCD6 rs4957014 were 5'TGGTGTTTCATACCATTGACACTTGC-3' and 5'CTCAGAACCAAGCAGGTTCCTTCA-3', respectively. As for PDCD6 rs3756712, the DNA sequences of the forward and reverse primers were 5'- TACAGTGGCAAAG GACCACA-3' and 5'-CACATTCCAGCACTCACCAC-3', respectively. Following PCR amplification, the products of PDCD6 rs4957014 and rs3756712 were subject to restriction enzyme digestion with $\mathrm{HphI}$ and RsaI (New England BioLabs, Ipswich, MA, USA), respectively. As for PDCD6 rs4957014, the digestible $G$ allele was cut into 113- and 13-base pair contigs, while the indigestible $\mathrm{T}$ allele was left intact as a 126-base pair long contig. As for PDCD6 rs3756712, the digestible $G$ allele was cut into 113- and 13base pair contigs, while the indigestible $\mathrm{T}$ allele was left intact as a 126-base pair long contig. Overall, the genotyping 
Table I Distribution of selected demographic data of the 358 patients with lung cancer and the 716 matched controls

\begin{tabular}{|c|c|c|c|c|c|c|c|}
\hline \multirow[t]{2}{*}{ Characteristics } & \multicolumn{3}{|c|}{ Controls $(n=7 \mid 6)$} & \multicolumn{3}{|c|}{ Patients $(n=358)$} & \multirow[t]{2}{*}{ p-value ${ }^{a}$} \\
\hline & $\mathbf{n}$ & $\%$ & Mean (SD) & $\mathbf{n}$ & $\%$ & Mean (SD) & \\
\hline Age (years) & & & $64.8(6.8)$ & & & $64.0(6.9)$ & $0.587 I$ \\
\hline Gender & & & & & & & 0.3642 \\
\hline Male & 488 & $68.1 \%$ & & 254 & $70.9 \%$ & & \\
\hline Female & 228 & $31.9 \%$ & & 104 & $29.1 \%$ & & 0.3642 \\
\hline \multicolumn{8}{|l|}{ Smoking status } \\
\hline Ever smokers & 563 & $78.6 \%$ & & 293 & $81.8 \%$ & & \\
\hline Non-smokers & 153 & $21.4 \%$ & & 65 & $18.2 \%$ & & 0.2282 \\
\hline \multicolumn{8}{|l|}{ Histology } \\
\hline Adenocarcinoma & & & & 218 & $60.9 \%$ & & \\
\hline SCC & & & & 106 & $29.6 \%$ & & \\
\hline Other & & & & 34 & $9.5 \%$ & & \\
\hline
\end{tabular}

Note: ${ }^{\text {BBased }}$ on Chi-squared test.

Abbreviations: SCC, squamous cell carcinoma; SD, standard deviation.

process was performed by 2 researchers independently and blindly. Five percent of the samples for PDCD6 were randomly selected for direct sequencing, and the results from PCR-restriction fragment length polymorphism analysis and direct sequencing were $100 \%$ concordant with each other.

\section{Statistical analyses}

As for sample size, the case and control groups were comprised of 358 and 716 individuals, respectively. To ensure that the controls used were representative of the general population and to exclude the possibility of genotyping errors, the deviation of the genotype frequencies of PDCD6 among the controls from those expected under the assumptions of Hardy-Weinberg equilibrium was assessed using the goodness-of-fit test. Mainly, Pearson's chi-square test was used to compare the distribution of PDCD6 genotypes and alleles between the case and control groups (Tables 2 and 3) or between other comparison subgroups (Tables 1 and 4, and Figures 1 and 2). The associations between the PDCD6 genotypes and lung cancer risk were estimated by computing ORs and their corresponding 95\% CIs with logistic regression analysis. Any value with $p<0.05$ was taken to be statistically significant.

\section{Results}

The frequency distributions of age, gender, and smoking status for the 358 lung cancer patients and 716 controls are summarized in Table 1. The average ages of the cases and controls were 64.0 and 64.8 years, respectively, and were not significantly different from each other. The ratio of males to females was approximately 2.33 in both groups (Table 1). Since we also applied frequency matching with respect to personal smoking habits when recruiting the healthy controls, there was no difference in the distribution of smokers between the control and case groups (Table 1). According to the patients' histological data, the percentages by lung cancer subtype were $60.9 \%$, $29.6 \%$, and $9.5 \%$ for adenocarcinoma, squamous cell carcinoma, and other histology, respectively (Table 1).

Both PDCD6 polymorphisms rs4957014 and rs3756712 were successfully genotyped for 358 lung cancer patients and 716 control subjects, and the distributions of PDCD6 rs4957014 and rs3756712 genotypes for all the participants are presented, along with the statistical analysis, in Table 2. Importantly, the genotypes of PDCD6 rs4957014 were distributed differently between the lung cancer and non-cancer control groups ( $p=0.0058$ for the trend) (Table 2, top). In detail, the PDCD6 rs4957014 heterozygous variant GT was not associated with lung cancer risk (OR $=0.90,95 \%$ $\mathrm{CI}=0.69-1.16, p=0.4086$ ), while the homozygous GG genotype variant was significantly associated with decreased lung cancer risk (OR $=0.41,95 \%$ CI $=0.23-0.72, p=0.0013)$ (Table 2, top). In the recessive model, the results showed that the GG genotype of PDCD6 rs4957014 was associated with decreased lung cancer risk, compared with the TT + GT genotype (Table 2 middle). In the dominant model, the differential distribution of the GT + GG versus wild-type TT genotypes was not so obvious between the lung cancer and control groups (Table 3, bottom). As for PDCD6 rs3756712, the results of codominant, recessive, and dominant models all showed that no genotype of PDCD6 rs3756712 was associated with lung cancer risk (Table 3). 
Table 2 Distribution of PDCD6 rs4957014 genotypes among the 358 patients with lung cancer and the 716 matched controls

\begin{tabular}{|c|c|c|c|c|c|c|c|}
\hline \multirow[t]{2}{*}{ Genetic model } & \multirow[t]{2}{*}{ Genotype } & \multicolumn{2}{|c|}{ Controls } & \multicolumn{2}{|c|}{ Patients } & \multirow[t]{2}{*}{ OR (95\% Cl) } & \multirow[t]{2}{*}{ p-value } \\
\hline & & $\mathbf{n}$ & $\%$ & $\mathbf{n}$ & $\%$ & & \\
\hline $\begin{array}{l}\text { rs49570I4 } \\
\text { Codominant }\end{array}$ & $\begin{array}{l}\text { TT } \\
\text { GT } \\
\text { GG } \\
P_{\text {trend }}\end{array}$ & $\begin{array}{l}323 \\
319 \\
74\end{array}$ & $\begin{array}{l}45.1 \% \\
44.6 \% \\
10.3 \%\end{array}$ & $\begin{array}{l}181 \\
160 \\
17\end{array}$ & $\begin{array}{l}50.6 \% \\
44.7 \% \\
4.7 \%\end{array}$ & $\begin{array}{l}\text { I.00 (reference) } \\
0.90(0.69-\mathrm{I} .16) \\
\mathbf{0 . 4 I}(\mathbf{0 . 2 3 - 0 . 7 2 )}\end{array}$ & $\begin{array}{l}0.4086 \\
0.0013 \\
0.0058\end{array}$ \\
\hline Recessive & $\begin{array}{l}\mathrm{TT}+\mathrm{GT} \\
\mathrm{GG}\end{array}$ & $\begin{array}{l}642 \\
74\end{array}$ & $\begin{array}{l}89.7 \% \\
10.3 \%\end{array}$ & $\begin{array}{l}341 \\
17\end{array}$ & $\begin{array}{l}95.3 \% \\
4.7 \%\end{array}$ & $\begin{array}{l}\text { I.00 (reference) } \\
\mathbf{0 . 4 3}(\mathbf{0 . 2 5}-\mathbf{0 . 7 4})\end{array}$ & 0.0019 \\
\hline Dominant & $\begin{array}{l}\text { TT } \\
\text { GT+GG }\end{array}$ & $\begin{array}{l}323 \\
393\end{array}$ & $\begin{array}{l}45.1 \% \\
54.9 \%\end{array}$ & $\begin{array}{l}181 \\
177\end{array}$ & $\begin{array}{l}50.6 \% \\
49.4 \%\end{array}$ & $\begin{array}{l}1.00 \text { (reference) } \\
0.80(0.62-1.04)\end{array}$ & 0.0918 \\
\hline
\end{tabular}

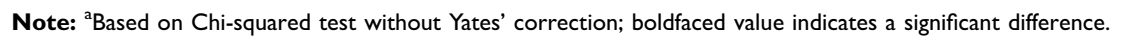

Abbreviations: $\mathrm{Cl}$, confidence interval; OR, odds ratio; Ptrend, $p$ for trend.

Table 3 Distribution of PDCD6 rs3756712 genotypes among the 358 patients with lung cancer and the 716 matched controls

\begin{tabular}{|c|c|c|c|c|c|c|c|}
\hline \multirow[t]{2}{*}{ Genetic model } & \multirow[t]{2}{*}{ Genotype } & \multicolumn{2}{|c|}{ Controls } & \multicolumn{2}{|c|}{ Patients } & \multirow[t]{2}{*}{ OR (95\% CI) } & \multirow[t]{2}{*}{$p$-value ${ }^{a}$} \\
\hline & & $\mathbf{n}$ & $\%$ & $\mathbf{n}$ & $\%$ & & \\
\hline \multicolumn{8}{|l|}{ rs37567II2 } \\
\hline \multirow[t]{4}{*}{ Codominant } & TT & 398 & $55.6 \%$ & 210 & $58.7 \%$ & I.00 (reference) & \\
\hline & GT & 254 & $35.5 \%$ & 127 & $35.4 \%$ & $0.95(0.72-1.24)$ & 0.6969 \\
\hline & GG & 64 & $8.9 \%$ & 21 & $5.9 \%$ & $0.62(0.37-1.05)$ & 0.0716 \\
\hline & $P_{\text {trend }}$ & & & & & & 0.1974 \\
\hline \multirow[t]{2}{*}{ Recessive } & $\mathrm{TT}+\mathrm{GT}$ & 652 & $91.2 \%$ & 337 & $94.1 \%$ & 1.00 (reference) & \\
\hline & GG & 64 & $8.9 \%$ & 21 & $5.9 \%$ & $0.63(0.38-1.06)$ & 0.0544 \\
\hline \multirow[t]{2}{*}{ Dominant } & $\mathrm{TT}$ & 398 & $55.6 \%$ & 210 & $58.7 \%$ & I.00 (reference) & \\
\hline & $\mathrm{GT}+\mathrm{GG}$ & 318 & $44.4 \%$ & 148 & $41.3 \%$ & $0.88(0.68-1.14)$ & 0.3382 \\
\hline
\end{tabular}

Note: 'Based on Chi-squared test without Yates' correction .

Abbreviations: $\mathrm{Cl}$, confidence interval; OR, odds ratio; Ptrend, $p$ for trend.

In order to confirm the findings presented in Tables 2 and 3, analysis of the allelic frequency distribution for PDCD6 rs4957014 and rs3756712 was performed, and the results are summarized in Table 4. The data showed that the T allele of PDCD6 rs4957014 was associated with a decreased risk of lung cancer, compared with the $\mathrm{G}$ allele. On the other hand, neither the T nor the $G$ allele of PDCD6 rs3756712 was associated with lung cancer risk (Table 4).

In order to determine the association between the rs4957014 polymorphism of PDCD6 and certain clinical pathologic features, we conducted a stratified analysis of the genotype distribution among patients and healthy controls according to their gender and smoking status, respectively (Figures 1 and 2). First, lung cancer patients and controls were stratified according to their gender, and the ORs were analyzed. The results showed that male participants carrying the homologous variant GG genotypes at PDCD6 rs4957014 were at a decreased risk of lung cancer after adjustment for age, smoking, alcohol drinking, and habitual areca chewing (adjusted OR $=0.29,95 \%$ $\mathrm{CI}=0.14-0.57$ ) (Figure 1, left). In contrast, there was no significant alteration of lung cancer risk associated with the GT or GG genotypes of PDCD6 rs4957014 in females (Figure 1, right). Then, lung cancer patients and controls were stratified similarly according to smoking status, and the adjusted ORs were analyzed. The results showed that ever smokers carrying the homologous GG genotypes at PDCD6 rs4957014 were at a decreased risk for lung cancer after adjustment for age, gender, alcohol drinking, and 
Table 4 Distribution of PDCD6 rs49570I4 and rs37567/2 allelic frequencies among the 358 patients with lung cancer and the 716 matched controls

\begin{tabular}{|c|l|l|l|l|l|l|}
\hline & Controls & $\%$ & Patients & $\%$ & OR (95\% Cl) & $\mathbf{P}$-value \\
\hline rs49570I4 & & & & & \\
Allele T & 965 & $67.4 \%$ & 522 & $72.9 \%$ & 1.00 (reference) \\
Allele G & 467 & $32.6 \%$ & 194 & $29.1 \%$ & $\mathbf{0 . 7 7}(\mathbf{0 . 6 3 - 0 . 9 4 )}$ & $\mathbf{0 . 0 0 9 0}$ \\
\hline rs37567I2 & & & & & & \\
Allele T & 1050 & $73.3 \%$ & 547 & $76.4 \%$ & 1.00 (reference) \\
Allele G & 382 & $26.7 \%$ & 169 & $23.6 \%$ & $0.85(0.69-1.05)$ & 0.1242 \\
\hline
\end{tabular}

Note: 'Based on Chi-squared test without Yates' correction; boldfaced value indicates a significant difference.

Abbreviations: $\mathrm{Cl}$, confidence interval; OR, odds ratio.

A Males

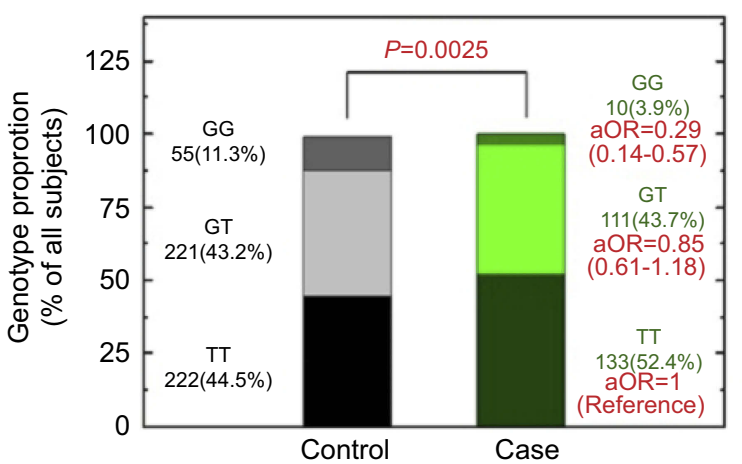

B Females

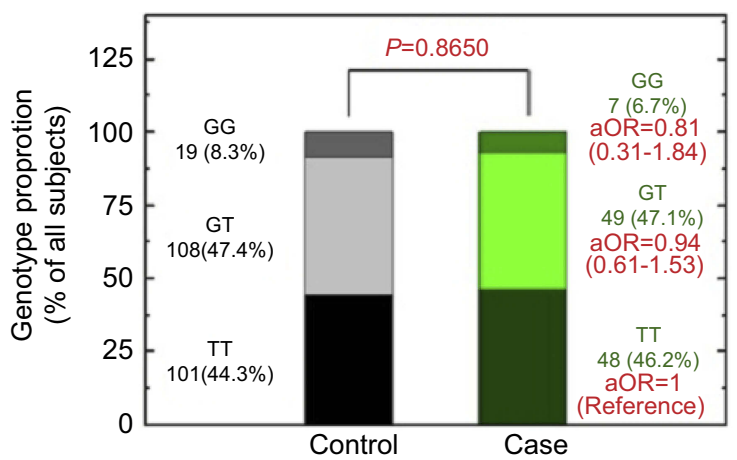

Figure I Contribution of PDCD6 rs49570I4 genotype to the lung cancer after stratification by gender. The distributions of TT, GT, and GG genotypes at PDCD6 rs49570 I4 among males (A) and females (B). Adjusted odds ratios (aORs) were estimated with multivariate logistic regression analysis after adjusted for age, smoking, alcohol drinking, and areca chewing status.

A Non-smokers

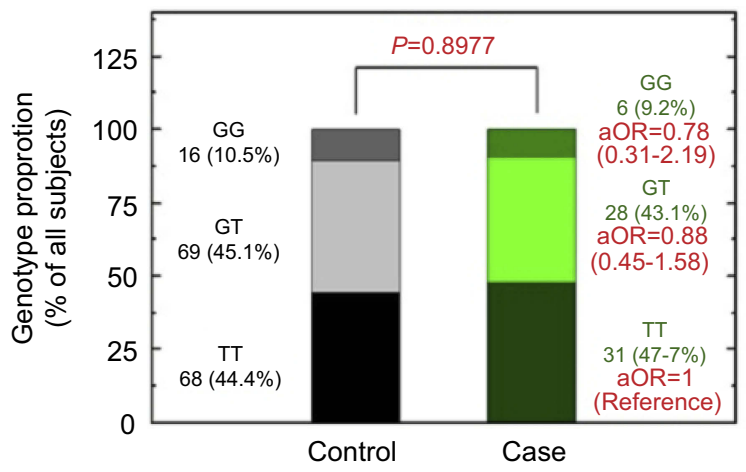

B Smokers

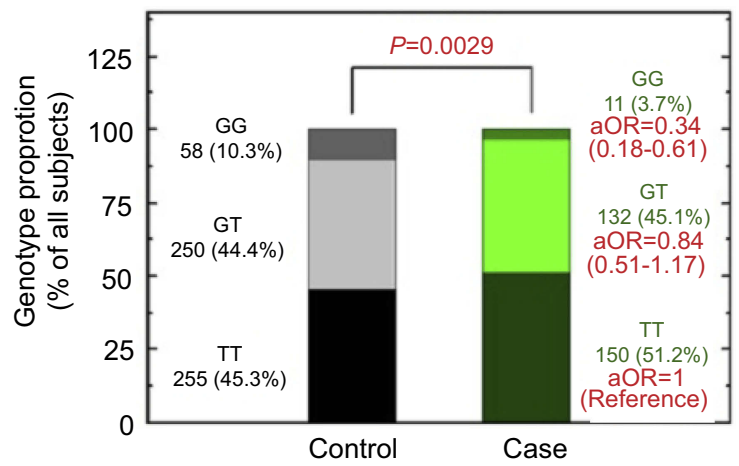

Figure 2 Contribution of PDCD6 rs49570I4 genotype to the lung cancer after stratification by smoking status. The distributions of TT, GT, and GG genotypes at PDCD6 rs4957014 among non-smokers (A) and smokers (B). Adjusted odds ratios (aORs) were estimated with multivariate logistic regression analysis after adjusted for age, gender, alcohol drinking, and areca chewing status.

habitual areca chewing (adjusted OR $=0.34,95 \%$ $\mathrm{CI}=0.18-0.61$ ) (Figure 2, right). In contrast, there was no significant alteration of lung cancer risk in non-smokers with the GT or GG genotypes of PDCD6 rs4957014
(Figure 2, left). In addition, there was no correlation of the studied genotypes of PDCD6 with several clinical indexes, including different histologies, TNM classification, staging, and survival status (data not shown). 


\section{Discussion}

PDCD6 has been identified as an apoptosis-related gene, ${ }^{23}$ and its encoded protein plays a role as a pro-apoptotic factor in $\mathrm{Ca}^{2+}$-dependent T-cell receptor-induced programmed cell death. ${ }^{33}$ On the other hand, PDCD6 also exerts an anti-apoptotic action in HeLa cells by facilitating the passage of proliferating cells through the G2/M cell cycle checkpoints. ${ }^{34}$ These dual functions of PDCD6 may be explained by the fact that it is a $\mathrm{Ca}^{2+}$-binding protein, and after being activated, PDCD6 can interact with various intracellular proteins containing Pro-rich regions, such as Alix (ALG-2-interacting protein X), ${ }^{35}$ annexins VII and $\mathrm{XI},{ }^{36} \mathrm{Sec} 31 \mathrm{~A}$ (SEC31 homolog A), ${ }^{27}$ and TSG101 (tumor susceptibility gene 101$),{ }^{35}$ in a $\mathrm{Ca}^{2+}$-dependent manner. The knockout of PDCD6 in mice did not block apoptosis, indicating that PDCD6 may have some functionally redundant partners. ${ }^{29}$ From the viewpoint of cancer genomics, there have only been a few articles reporting the contribution of PDCD6 genotypes to cancers, including ovarian cancer, ${ }^{37}$ endometrial cancer, ${ }^{38}$ breast cancer, ${ }^{39}$ cervical cancer, ${ }^{40}$ and lung cancer. ${ }^{32}$ Interestingly, the investigated cancers in these previous studies were all gender related; nonetheless, the results were controversial and inconclusive. Lung cancer is also one of the smoking-related cancers. Therefore, in the current study, the contribution of PDCD6 (rs4957014 and rs3756712) genotypes, gender, and smoking status to lung cancer risk was evaluated. The highlights of the study included (1) the homozygous GG genotype at PDCD6 rs4957014 was significantly associated with a decreased risk of lung cancer in codominant and recessive models (Table 2); (2) The allelic frequency analysis supports the findings outlined in point 1 , showing that the G allele of PDCD6 rs4957014 was associated with a decreased lung cancer risk (Table 4); and (3) The determinant effect of the PDCD6 genotype on lung cancer risk was more obvious among males (Figure 1) and smokers (Figure 2). The protective effect of the rs4957014 polymorphism of PDCD6 on lung cancer risk found here was supported by the findings of Zhou and He. ${ }^{32,40}$ On the other hand, it has been revealed that the rs3756712 and rs4957014 polymorphisms of PDCD6 significantly increased the risk of endometrial cancer. ${ }^{38}$ Further validation in larger and different populations are needed for a more precise and meaningful meta-analysis.

Gender is a risk factor for lung cancer. Although the possible mechanism(s) is still largely unknown, it is thought that endocrine-related factors play a critical part in the gender-based difference in lung cancer risk. ${ }^{41}$ In the National Health Insurance Research Database investigating 33,919 patients with lung cancer recorded from 2002 to 2008 in Taiwan, about two-thirds of the newly diagnosed patients were males, ${ }^{42}$ with the ratio being very similar to the gender ratio in this study. In recent years, there has been an increasing trend toward female patients with lung cancer and female smokers in Taiwan, as the prevalence and mortality rates in females with non-smallcell lung cancer adenocarcinoma are very high in Taiwan. Therefore, we were interested in whether the genotype of PDCD6 rs4957014 contributes to the gender difference in lung cancer susceptibility. After stratification by gender, it was found that the genotypes of PDCD6 rs4957014 were differently distributed among males but not among females (Figure 1). One explanation for the trend in female patients with lung cancer is the increase in cigarette consumption among females. The results of epidemiological studies suggest that after controlling for the number of cigarettes smoked, women have a 3-fold higher risk of suffering from lung cancer than men. ${ }^{41}$

As mentioned above, cigarette smoking is also a wellknown risk factor for lung cancer. Cigarette smoke may enhance remodeling in the developing human airway smooth muscle through hyperplasia and alteration of the extracellular microenvironment, thus contributing to the development of neonatal and pediatric airway disease. ${ }^{43}$ In addition, tobacco smoking can induce DNA lesions, and defects in repair of tobacco carcinogen-induced DNA adducts may contribute to carcinogenesis. ${ }^{44}$ Therefore, in the last part, the interaction of the genotype of PDCD6 and cigarette smoking status of the participants was examined. As expected, the results showed that the genotypic distribution of the variant genotypes of PDCD6 rs4957014 was significantly different between lung cancer and control subgroups who were ever smokers (Figure 2, right). On the contrary, no differential distribution was observed among non-smokers (Figure 2, left). There was no phenotypic assay reporting that the PDCD6 rs4957014 T allele attenuated its capacity to promote those cells with too much DNA damage or too many DNA adducts caused by smoking as those cells with $G$ allele. Lung cells that survive with unrepaired DNA damage will accumulate genomic instability more easily under chronic exposure to cigarette smoking and thus, increase the risk of lung cancer. Further investigations using cells from patients with different genotypes of PDCD6 rs4957014 should be conducted to explore the joint 
effects of tobacco smoking and PDCD6 rs4957014 on cancer risk. Likewise, future investigations should be designed based on cells from different genders, drinking status, and other lung cancer risk factors.

There are many genome-wide association studies (GWAS) for lung cancer to date. The GWAS methodology is expert in high-throughput and depending on datamining analysis to annotate their work. However, these studies cost a lot and the significant SNPs found by GWAS frequently are not locate in or near a gene and may not easily accessed with further functional analysis and annotation. Therefore, to investigate the hypothesis-driven candidate gene and to examine the association between these SNPs on the gene and the risk of lung cancer were still valuable.

In conclusion, the current study provides solid evidence that the G allele of PDCD6 rs4957014 can serve as a protective biomarker for lung cancer risk in the Taiwanese population, especially among males and smokers.

\section{Acknowledgments}

We are grateful to Tissue-bank of China Medical University Hospital and doctors/nurses under Prof. Hsia's leadership for their excellent sample collection and technical assistance. The technical assistance from Yun-Chi Wang and the consultants of statistical analysis from Cheng-Li Lin are very helpful in manuscript preparation. This study was supported partially by research grants from China Medical University (DMR108019) to Shen and from Taiwan Ministry of Health and Welfare Clinical Trial and Research Center of Excellence (MOHW108-TDU-B-212-133004).

\section{Disclosure}

The authors report no conflicts of interest in this work.

\section{References}

1. Bray F, Ferlay J, Soerjomataram I, Siegel RL, Torre LA, Jemal A. Global cancer statistics 2018: GLOBOCAN estimates of incidence and mortality worldwide for 36 cancers in 185 countries. CA Cancer J Clin. 2018;68:394-424. doi:10.3322/caac.21492

2. Siegel RL, Miller KD, Jemal A. Cancer statistics, 2015. CA Cancer J Clin. 2015;65:5-29. doi:10.3322/caac.21254

3. Torre LA, Bray F, Siegel RL, Ferlay J, Lortet-Tieulent J, Jemal A. Global cancer statistics, 2012. CA Cancer J Clin. 2015;65:87-108. doi:10.3322/caac. 21262

4. Li Z, Chen L, Qin Z. Paradoxical roles of IL-4 in tumor immunity. Cell Mol Immunol. 2009;6:415-422. doi:10.1038/cmi.2009.53

5. Sculier JP, Chansky K, Crowley JJ, Van Meerbeeck J, Goldstraw P. International staging $\mathrm{C}$ and participating I. The impact of additional prognostic factors on survival and their relationship with the anatomical extent of disease expressed by the 6th Edition of the TNM classification of malignant tumors and the proposals for the 7th edition. $J$ Thorac Oncol. 2008;3:457-466. doi:10.1097/ JTO.0b013e31816de2b8
6. Hasegawa Y, Ando M, Maemondo M, et al. The role of smoking status on the progression-free survival of non-small cell lung cancer patients harboring activating epidermal growth factor receptor (EGFR) mutations receiving first-line EGFR tyrosine kinase inhibitor versus platinum doublet chemotherapy: a meta-analysis of prospective randomized trials. Oncologist. 2015;20:307-315. doi:10.1634/ theoncologist.2014-0285

7. Bhatt VR, Batra R, Silberstein PT, Loberiza FR Jr., Ganti AK. Effect of smoking on survival from non-small cell lung cancer: a retrospective Veterans' Affairs Central Cancer Registry (VACCR) cohort analysis. Med Oncol. 2015;32:339. doi:10.1007/s12032014-0339-3

8. Wang Y, Qian W, Yuan B. A graphical model of smoking-induced global instability in lung cancer. IEEE/ACM Trans Comput Biol Bioinform. 2018;15:1-14. doi:10.1109/TCBB.2016.2599867

9. Ji YN, Wang Q, Suo LJ. CYP1A1 Ile462Val polymorphism contributes to lung cancer susceptibility among lung squamous carcinoma and smokers: a meta-analysis. PLoS One. 2012;7:e43397. doi:10.1371/journal.pone.0043397

10. Spitz MR, Gorlov IP, Dong Q, et al. Multistage analysis of variants in the inflammation pathway and lung cancer risk in smokers. Cancer Epidemiol Biomarkers Prev. 2012;21:1213-1221. doi:10.1158/10559965.EPI-12-0352-T

11. Hsia TC, Chang WS, Liang SJ, et al. Interleukin-10 (IL-10) promoter genotypes are associated with lung cancer risk in Taiwan males and smokers. Anticancer Res. 2014;34:7039-7044.

12. Hsia TC, Chang WS, Chen WC, et al. Genotype of DNA doublestrand break repair gene $\mathrm{XRCC} 7$ is associated with lung cancer risk in Taiwan males and smokers. Anticancer Res. 2014;34:70017005.

13. Hsia TC, Tsai CW, Liang SJ, et al. Effects of ataxia telangiectasia mutated (ATM) genotypes and smoking habits on lung cancer risk in Taiwan. Anticancer Res. 2013;33:4067-4071.

14. Liu CJ, Hsia TC, Tsai RY, et al. The joint effect of hOGG1 single nucleotide polymorphism and smoking habit on lung cancer in Taiwan. Anticancer Res. 2010;30:4141-4145.

15. Liu CJ, Hsia TC, Wang RF, et al. Interaction of cyclooxygenase 2 genotype and smoking habit in Taiwanese lung cancer patients. Anticancer Res. 2010;30:1195-1199.

16. Wu MF, Wang YC, Li HT, et al. The contribution of interleukin-12 genetic variations to taiwanese lung cancer. Anticancer Res. 2018;38:6321-6327. doi:10.21873/anticanres.12989

17. Chuang $\mathrm{CL}$, Wang $\mathrm{CH}$, Hsu $\mathrm{CH}$, et al. Contribution of double-strand break repair gene nijmegen breakage syndrome 1 genotypes, gender difference and smoking status to taiwanese lung cancer. Anticancer Res. 2017;37:2417-2423. doi:10.21873/anticanres.11581

18. Govindan R. Lung cancer in never smokers: a new hot area of research. Lancet Oncol. 2010;11:304-305. doi:10.1016/S1470-2045 (10)70057-7

19. Liu YL, Xu Y, Li F, Chen H, Guo SL. CYP2A6 deletion polymorphism is associated with decreased susceptibility of lung cancer in Asian smokers: a meta-analysis. Tumour Biol. 2013;34:2651-2657. doi:10.1007/s13277-013-0815-y

20. Lo YL, Hsiao CF, Jou YS, et al. Polymorphisms of MLH1 and MSH2 genes and the risk of lung cancer among never smokers. Lung Cancer. 2011;72:280-286. doi:10.1016/j.lungcan.2010.10.009

21. Wu X, Wang L, Ye Y, et al. Genome-wide association study of genetic predictors of overall survival for non-small cell lung cancer in never smokers. Cancer Res. 2013;73:4028-4038. doi:10.1158/ 0008-5472.CAN-12-4033

22. Lissowska J, Foretova L, Dabek J, et al. Family history and lung cancer risk: international multicentre case-control study in Eastern and Central Europe and meta-analyses. Cancer Causes Control. 2010;21:1091-1104. doi:10.1007/s10552-010-9537-2

23. Vito P, Lacana E, D'Adamio L. Interfering with apoptosis: ca(2 +)-binding protein ALG-2 and Alzheimer's disease gene ALG-3. Science. 1996;271:521-525. doi:10.1126/science.271.5248.521 
24. Jung YS, Kim KS, Kim KD, Lim JS, Kim JW, Kim E. Apoptosislinked gene 2 binds to the death domain of Fas and dissociates from Fas during Fas-mediated apoptosis in Jurkat cells. Biochem Biophys Res Commun. 2001;288:420-426. doi:10.1006/bbrc.2001.5769

25. Wu Y, Pan S, Che S, et al. Overexpression of Hp95 induces G1 phase arrest in confluent HeLa cells. Differentiation. 2001;67:139-153. doi:10.1046/j.1432-0436.2001.670406.x

26. Hwang IS, Jung YS, Kim E. Interaction of ALG-2 with ASK1 influences ASK1 localization and subsequent JNK activation. FEBS Lett. 2002;529:183-187. doi:10.1016/s0014-5793(02)03329-x

27. Shibata H, Suzuki H, Yoshida H, Maki M. ALG-2 directly binds Sec31A and localizes at endoplasmic reticulum exit sites in a $\mathrm{Ca} 2$ +-dependent manner. Biochem Biophys Res Commun. 2007;353:756763. doi:10.1016/j.bbrc.2006.12.101

28. Rao RV, Poksay KS, Castro-Obregon S, et al. Molecular components of a cell death pathway activated by endoplasmic reticulum stress. $J$ Biol Chem. 2004;279:177-187. doi:10.1074/jbc.M304490200

29. Jang IK, Hu R, Lacana E, D’Adamio L, Gu H. Apoptosis-linked gene 2deficient mice exhibit normal T-cell development and function. Mol Cell Biol. 2002;22:4094 4100. doi:10.1128/mcb.22.12.4094-4100.2002

30. Zhang K, Zhou B, Shi S, Song Y, Zhang L. Variations in the PDCD6 gene are associated with increased uterine leiomyoma risk in the Chinese. Genet Test Mol Biomarkers. 2013;17:524-528. doi: $10.1089 / \mathrm{gtmb} .2012 .0461$

31. la Cour JM, Mollerup J, Winding P, Tarabykina S, Sehested M, Berchtold MW. Up-regulation of ALG-2 in hepatomas and lung cancer tissue. AM J Pathol. 2003;63:81-89. doi:10.1016/S00029440(10)63632-2

32. He YQ, Zhou B, Shi SQ, Zhang L, Li WM. Genetic variation in PDCD6 and susceptibility to lung cancer. Asian Pac J Cancer Prev. 2012;13:4689-4693. doi:10.7314/apjcp.2012.13.9.4689

33. D'Adamio L, Lacana E, Vito P. Functional cloning of genes involved in T-cell receptor-induced programmed cell death. Semin Immunol. 1997;9:17-23.

34. Hoj BR, la Cour JM, Mollerup J, Berchtold MW. ALG-2 knockdown in HeLa cells results in G2/M cell cycle phase accumulation and cell death. Biochem Biophys Res Commun. 2009;378:145-148. doi:10.1016/j.bbrc.2008.11.021
35. Suzuki H, Kawasaki M, Inuzuka $\mathrm{T}$, et al. The mechanism of $\mathrm{Ca} 2$ +-dependent recognition of Alix by ALG-2: insights from X-ray crystal structures. Biochem Soc Trans. 2009;37:190-194. doi:10.1042/ BST0370190

36. Satoh H, Nakano Y, Shibata H, Maki M. The penta-EF-hand domain of ALG-2 interacts with amino-terminal domains of both annexin VII and annexin XI in a Ca2+-dependent manner. Biochim Biophys Acta. 2002;1600:61-67. doi:10.1016/s1570-9639(02)00445-4

37. Su D, Xu H, Feng J, et al. PDCD6 is an independent predictor of progression free survival in epithelial ovarian cancer. J Transl Med. 2012;10:31. doi:10.1186/1479-5876-10-233

38. Yuan M, Song Y, You D, et al. Association between single nucleotide polymorphisms in the programmed cell death 6 gene and the risk of endometrial cancer in Chinese Han women. Int J Clin Exp Pathol. 2017;10:11169-11178.

39. Zhang L, Chen X, Liu B, Han J. MicroRNA-124-3p directly targets PDCD6 to inhibit metastasis in breast cancer. Oncol Lett. 2018;15:984-990. doi:10.3892/ol.2017.7358

40. Zhou B, Bai P, Xue H, et al. Single nucleotide polymorphisms in PDCD6 gene are associated with the development of cervical squamous cell carcinoma. Fam Cancer. 2015;14:1-8. doi:10.1007/ s10689-014-9767-7

41. Gasperino J. Gender is a risk factor for lung cancer. Med Hypotheses. 2011;76:328-331. doi:10.1016/j.mehy.2010.10.030

42. Wang BY, Huang JY, Cheng CY, Lin CH, Ko J, Liaw YP. Lung cancer and prognosis in taiwan: a population-based cancer registry. $J$ Thorac Oncol. 2013;8:1128-1135. doi:10.1097/JTO.0b013e31829ceba4

43. Vogel ER, VanOosten SK, Holman MA, et al. Cigarette smoke enhances proliferation and extracellular matrix deposition by human fetal airway smooth muscle. Am J Physiol Lung Cell Mol Physiol. 2014;307:L978-L986. doi:10.1152/ajplung.00111.2014

44. Wei Q, Cheng L, Amos CI, et al. Repair of tobacco carcinogeninduced DNA adducts and lung cancer risk: a molecular epidemiologic study. J Natl Cancer Inst. 2000;92:1764-1772. doi:10.1093/jnci/ 92.21.1764
OncoTargets and Therapy

\section{Publish your work in this journal}

OncoTargets and Therapy is an international, peer-reviewed, open access journal focusing on the pathological basis of all cancers, potential targets for therapy and treatment protocols employed to improve the management of cancer patients. The journal also focuses on the impact of management programs and new therapeutic agents and protocols on patient perspectives such as quality of life, adherence and satisfaction. The manuscript management system is completely online and includes a very quick and fair peer-review system, which is all easy to use. Visit http://www.dovepress.com/ testimonials.php to read real quotes from published authors. 